University of Wollongong

Research Online

Australian Institute for Innovative Materials -

Papers

Australian Institute for Innovative Materials

$1-1-2019$

\title{
A non-enzymatic photoelectrochemical glucose sensor based on BiVO4 electrode under visible light
}

\author{
Shan Wang \\ Beihang University \\ Shaoping Li \\ Beihang University \\ Wenwen Wang \\ Beihang University \\ Mengting Zhao \\ Beihang University, University of Wollongong \\ Jiaofeng Liu \\ Beihang University
}

See next page for additional authors

Follow this and additional works at: https://ro.uow.edu.au/aiimpapers

Part of the Engineering Commons, and the Physical Sciences and Mathematics Commons

Research Online is the open access institutional repository for the University of Wollongong. For further information contact the UOW Library: research-pubs@uow.edu.au 


\title{
A non-enzymatic photoelectrochemical glucose sensor based on BiVO4 electrode under visible light
}

\begin{abstract}
A non-enzymatic photoelectrochemical (PEC) glucose sensor based on nanoporous bismuth vanadate (BiVO 4 ) electrode is fabricated on fluorine doped tin oxide by electrochemical deposition. The photogenerated holes of BiVO 4 show a strong oxidizing ability, with adsorption of glucose on the surface of BiVO 4 , agreeing well with the classical Langmuir adsorption model. Under visible light irradiation, the glucose molecules adsorbed on the BiVO 4 electrode surface can be oxidized by the photogenerated holes, which results in increased photocurrent. The fabricated BiVO 4 non-enzymatic photoelectrochemical sensor shows outstanding catalytic activity, favourable selectivity, good reproducibility, and long-term stability for glucose detection under optimized conditions. The linear range was $0-5 \mathrm{mM}$ (correlation coefficient, $\mathrm{R}=0.997$ ) with a detection limit of $0.13 \mu \mathrm{mol} \mathrm{L}-1$ (signal-to-noise = 3). In addition, the proposed PEC sensor was successfully applied to detect glucose in human serum samples. Our work provides a new strategy for the non-enzymatic detection of glucose.
\end{abstract}

\section{Keywords}

visible, electrode, light, under, non-enzymatic, photoelectrochemical, glucose, sensor, bivo4

\section{Disciplines}

Engineering | Physical Sciences and Mathematics

\section{Publication Details}

Wang, S., Li, S., Wang, W., Zhao, M., Liu, J., Feng, H., Chen, Y., Gu, Q., Du, Y. \& Hao, W. (2019). A nonenzymatic photoelectrochemical glucose sensor based on BiVO4 electrode under visible light. Sensors and Actuators, B: Chemical, 291 34-41.

\section{Authors}

Shan Wang, Shaoping Li, Wenwen Wang, Mengting Zhao, Jiaofeng Liu, Haifeng Feng, Yiming Chen, Qi Gu, Yi Du, and Weichang Hao 


\section{A non-enzymatic photoelectrochemical glucose sensor based on $\mathrm{BiVO}_{4}$ electrode under visible light}

Shan Wang ${ }^{\mathrm{a}, \mathrm{c}}$, Shaoping $\mathrm{Li}^{\mathrm{a}, \mathrm{c}}$, Wenwen Wang ${ }^{\mathrm{a}, \mathrm{c}}$, Mengting Zhao ${ }^{\mathrm{a}, \mathrm{b}, \mathrm{c}}$, Jiaofeng Liu ${ }^{\mathrm{a}, \mathrm{c}}$, Haifeng Feng ${ }^{\mathrm{a}, \mathrm{b}, \mathrm{c}}$, Yiming Chen $^{\text {d }}$, Qi Gu ${ }^{\mathrm{e}}$, Yi Du ${ }^{\mathrm{a}, \mathrm{b}, \mathrm{c}}$, Weichang $\mathrm{Hao}^{\mathrm{a}, \mathrm{b}, \mathrm{c}^{*}}$

${ }^{a}$ School of Physics and Key Laboratory of Micro-Nano Measurement, Manipulation and Physics, Ministry of Education, Beihang University, Beijing 100191, China.

${ }^{\mathrm{b}}$ Institute for Superconducting and Electronic Materials, University of Wollongong, NSW 2500, Australia.

${ }^{\mathrm{c}}$ BUAA-UOW Joint Research Centre, Beihang University, Beijing 100191, China.

d Beihang Experimental School, Beijing 100191, China.

e State Key Laboratory of Membrane Biology, Institute of Zoology, Chinese Academy of Sciences, Beijing 100101, China.

* To whom correspondence should be addressed. Email: whao@buaa.edu.cn.

ABSTRACT: A non-enzymatic photoelectrochemical (PEC) glucose sensor based on nanoporous bismuth vanadate $\left(\mathrm{BiVO}_{4}\right)$ electrode is fabricated on fluorine doped tin oxide by electrochemical deposition. The photogenerated holes of $\mathrm{BiVO}_{4}$ show a strong oxidizing ability, with adsorption of glucose on the surface of $\mathrm{BiVO}_{4}$, agreeing well with the classical Langmuir adsorption model. Under visible light irradiation, the glucose molecules adsorbed on the $\mathrm{BiVO}_{4}$ electrode surface can be oxidized by the photogenerated holes, which results in increased photocurrent. The fabricated $\mathrm{BiVO}_{4}$ non-enzymatic photoelectrochemical sensor shows outstanding catalytic activity, favourable selectivity, good reproducibility, and long-term stability for glucose detection under optimized conditions. The linear range was $0-5 \mathrm{mM}$ (correlation coefficient, $R=0.997$ ) with a detection limit of $0.13 \mu \mathrm{mol} \mathrm{L}{ }^{-1}$ (signal-to-noise $=3$ ). In addition, the proposed PEC sensor was successfully applied to detect glucose in human serum samples. Our work provides a new strategy for the non-enzymatic detection of glucose.

Keywords: Non-enzymatic, Photoelectrochemical sensor, Visible light, Bismuth vanadate,

Glucose 


\section{Introduction}

Diabetes mellitus has been recognized as a worldwide disease which can lead to various functional disorders, even death in serious cases [1]. According to International Diabetes Federation (IDF) statistics, in the year 2017 alone, there were 425 million people living with diabetes, and the number was continuously increasing. Besides, it is estimated that approximately 4 million people between the ages of 20 and 79 died of diabetes in 2017, which was equivalent to one death every 8 seconds [2]. Therefore, glucose detection is vital for the diagnosis and treatment of diabetes mellitus [3-5]. Over the past few decades, considerable efforts have been made to develop sensitive, fast, and low-cost glucose biosensors [6-8]. Ever since the first development of an enzyme-modified electrode by Clark and Lyons in 1962, great progress has been made in the study of glucose oxidase (GOx) sensors $[9,10]$. Although good selectivity and desirable sensitivity can be achieved with enzymatic glucose sensors, their inherent drawbacks, such as intrusive chemical and thermal instability of the enzyme, severely hinder their practical application [11]. To overcome these disadvantages, research efforts have focused on developing non-enzyme glucose sensors, such as using noble metals, or charge-transfer-complex-based electrodes for the detection of glucose with high reliability and good device lifetime. These attempts still cannot fully substitute for enzymatic sensors in practical applications, however, owing to their intrinsic drawbacks [12-15]. For examples, noble metal modified electrodes are easily poisoned by the adsorbed intermediates [17]. The sensitivity of non-enzymatic sensors based on metal alloys is also suboptimal due to their high operating voltages [18].

Recently, photoelectrochemical (PEC) sensing has attracted substantial research interest for the detection of biomolecules [19-21]. Compared to conventional electrochemical methods, the PEC sensor has high sensitivity and a low background signal, which can be ascribed to its separate excitation source and detection signals [22]. Furthermore, the PEC sensor can simultaneously degrade the interfering substances and intermediate substances involved in glucose oxidation, avoiding chemical poisoning in detection [23]. Numerous photoactive materials have been deeply investigated for the preparation of PEC sensors, among which $\mathrm{TiO}_{2}$, as a commonly used photocatalyst, has received the most attention due to its excellent oxidation capability, high physical and chemical stability, and nontoxicity [24-28]. $\mathrm{TiO}_{2}$ suffers, however, from its large 
band-gap energy $\left(E_{\mathrm{g}}=3.2 \mathrm{eV}\right)$ and the rapid recombination rate of its photogenerated electron hole pairs, limiting its utilization in the visible light range [29, 30]. To improve the photocurrent and sensitivity, one of the most effective methods is to use new visible-light photocatalysts with narrow band gap [31-34]. $\mathrm{BiVO}_{4}$, with a monoclinic structure, has been widely developed as an excellent visible-light driven photocatalyst for photocatalytic degradation of organic pollutants and water splitting, due to its unique electronic band structure, high conduction band energy, good stability against photocorrosion, and nontoxicity relative to other visible-light active metal oxide semiconductors [35-41]. For example, Kudo et al fabricated a $\mathrm{BiVO}_{4}$ thin film electrode for efficient water splitting and obtained high photocurrent densities with an incident photon to converted electron (IPCE) value of $73 \%$ at $420 \mathrm{~nm}$ at $1.0 \mathrm{~V}$ vs. $\mathrm{Ag} / \mathrm{AgCl}$ [42]. Zhu et al reported that $\mathrm{BiVO}_{4}$ photoanodes with twin structure exhibited excellent photocatalytic activity towards water oxidation, benefiting from the enhanced charge separation and transport [43]. In addition, it was found that the photogenerated holes of $\mathrm{BiVO}_{4}$ had a strong oxidizing capability, so that they could directly oxidize the organic matter adsorbed on the electrode surface [37]. Research on its application in glucose detection, however, has been rarely explored. Based on these considerations, we have used nanoporous $\mathrm{BiVO}_{4}$ to construct a PEC glucose sensor as a substitute for $\mathrm{TiO}_{2}$, which will provide a new direction for the detection of glucose.

In this work, we present the fabrication of a non-enzymatic PEC glucose sensor based on nanoporous $\mathrm{BiVO}_{4}$ electrode for effective glucose detection under visible light irradiation. The synthesis and characterization of the $\mathrm{BiVO}_{4}$ electrode were systematically studied. The properties of the sensor, such as sensitivity, selectivity, and detection limit in glucose detection, are discussed in detail. Moreover, the proposed PEC sensor was successfully applied to detect glucose in human serum samples. It was found that the valence band maximum (VBM) of $\mathrm{BiVO}_{4}$ is relatively low, which endows the photogenerated holes with strong oxidizing ability, so that they can directly oxidize glucose molecules adsorbed on the electrode surface. In addition, the adsorption of glucose on the surface of $\mathrm{BiVO}_{4}$ was found to agree well with the classical Langmuir adsorption model. Besides the outstanding photocurrent response, it was also demonstrated that the resulting sensor shows favourable selectivity to glucose.

\section{Experimental section}




\subsection{Materials}

Fluorine doped tin oxide (FTO)-coated glass substrates were purchased from Yingkou OPV Tech New Energy Co., Ltd., and were sliced to $2.0 \times 1.0 \mathrm{~cm}^{2}$ pieces. KI was purchased from Macklin Chemicals. $p$-benzoquinone was purchased from Sinopharm Group Chemical Reagent Co., Ltd. $\mathrm{Bi}\left(\mathrm{NO}_{3}\right)_{3} \cdot 5 \mathrm{H}_{2} \mathrm{O}, \mathrm{HNO}_{3}, \mathrm{NaOH}$, dimethyl sulfoxide (DMSO), vanadyl acetylacetonate $\left(\mathrm{VO}(\mathrm{acac})_{2}\right)$, dopamine (DA), ascorbic acid (AA), uric acid (UA), and other chemicals were obtained from Beijing Blue Yi Chemical Products Co., Ltd. All chemical reagents are of analytical grade. Human serum samples were collected from Xuanwu Hospital Capital Medical University.

\subsection{Preparation of $\mathrm{BiVO}_{4}$ Electrode}

A mature and simple electrochemical deposition method was used to fabricate nanoporous $\mathrm{BiVO}_{4}$ electrodes on the FTO by the same method as reported in previous works [32]. In detail, the plating solution was prepared by dissolving $40 \mathrm{mM} \mathrm{Bi}\left(\mathrm{NO}_{3}\right)_{3} \cdot 5 \mathrm{H}_{2} \mathrm{O}$ in $50 \mathrm{~mL}$ of a $400 \mathrm{mM} \mathrm{KI}$ aqueous solution. The $\mathrm{pH}$ of the resulting opaque orange solution was adjusted to 1.75 by adding dilute $\mathrm{HNO}_{3}$, which converted the opaque solution to a transparent red-orange solution. This solution was mixed with $0.23 \mathrm{M} 1$, 4-benzoquinone in ethanol with stirring for a few minutes. A standard three-electrode cell was used for all electrodepositions, with a FTO working electrode, a platinum counter electrode, and an $\mathrm{Ag} / \mathrm{AgCl}(4 \mathrm{M} \mathrm{KCl})$ reference electrode. To obtain samples with different thickness, the electrodeposition time of 30, 90, 150, 210, 270, 330, 390, 450, and $550 \mathrm{~s}$ was adopted, respectively, at the same potential of $+0.13 \mathrm{~V}$. The as-prepared BiOI electrodes were purged thoroughly with deionized water, and then dried in an oven at $110{ }^{\circ} \mathrm{C}$. After that, $0.20 \mathrm{M}$ vanadyl acetylacetonate $\left(\mathrm{VO}(\mathrm{acac})_{2}\right)$ dissolved in dimethyl sulfoxide was dropped uniformly on the BiOI films, and they were then heated in a muffle furnace at $450{ }^{\circ} \mathrm{C}$ for $2 \mathrm{~h}$ with a ramping rate of $2{ }^{\circ} \mathrm{C} / \mathrm{min}$. Excessive $\mathrm{V}_{2} \mathrm{O}_{5}$ on the electrodes was removed by immersing them in $1.0 \mathrm{M} \mathrm{NaOH}$ for 30 min with mild stirring. The resultant $\mathrm{BiVO}_{4}$ electrodes were rinsed with ultrapure water and dried in air. The whole synthesis process of the proposed electrode was shown in Scheme 1.

\subsection{Characterization and Photoelectrochemical Measurements of the $\mathrm{BiVO}_{4}$ Electrode}

X-ray diffraction (XRD) was conducted with a X Pert Pro (PANalytical) diffractometer. Scanning 
electron microscopy (SEM) measurements were conducted with a HITACHI S-4800. Ultraviolet (UV)-visible diffuse reflectance spectra were collected on a Hitachi U3010 spectrophotometer. X-ray photoelectron spectroscopy (XPS) data were acquired on a PHI-5300 photoelectron spectrometer. The thickness of $\mathrm{BiVO}_{4}$ films was measured by the DEKTAK 6M stylus profiler. The electrodeposition process and PEC properties of the electrodes were carried out and investigated, respectively, in a conventional three-electrode cell in conjunction with a CHI650D electrochemical workstation (Chenghua, Shanghai). A $300 \mathrm{~W}$ Xenon lamp was employed as the light source with an intensity of $100 \mathrm{~mW} / \mathrm{cm}^{2}$. Biological procedures were completed under the guidelines of Institute of Zoology, Chinese Academy of Sciences.

\section{Results and Discussion}

\subsection{Characterization}

Fig. 1 displays the XRD patterns of the $\mathrm{BiOI}$ and $\mathrm{BiVO}_{4}$ films. In the BiOI, peaks at $29.6^{\circ}$, $31.7^{\circ}, 45.4^{\circ}$, and $55.2^{\circ}$ are observed, corresponding to the (102), (110), (200), and (102) planes, respectively, for the tetragonal phase of BiOI (JCPDS No. 10-0445). For the $\mathrm{BiVO}_{4}$ sample, the main diffraction peaks at $18.9^{\circ}$ and $28.9^{\circ}$ are well indexed to the monoclinic scheelite phase of $\mathrm{BiVO}_{4}$ (JCPDS No. 14-0688). The XRD patterns confirm that the electrodeposited BiOI film has been effectively converted to pure phase $\mathrm{BiVO}_{4}$. No additional diffraction peaks other than for the FTO substrate are observed. Moreover, the intensity of the diffraction peaks of $\mathrm{BiVO}_{4}$ indicates high crystallinity, which is beneficial to facilitate the separation of electron-hole pairs and prevent the recombination of photogenerated charge carriers in the bulk.

The morphology of the $\mathrm{BiOI}$ and $\mathrm{BiVO}_{4}$ samples were examined by SEM. As exhibited in the upper row of Fig. 2, the BiOI film is composed of extremely thin plates with ample space between them that have grown vertically on the FTO substrate. Consequently, a nanoporous $\mathrm{BiVO}_{4}$ film possessing an average particle size of $70 \mathrm{~nm}$ is obtained, as shown in the lower row of Fig. 2. It can be explained that, during the annealing process, the voids between the BiOI platelets effectively suppress the grain growth of $\mathrm{BiVO}_{4}$, leading to the formation of nanoporous $\mathrm{BiVO}_{4}$ electrode, which obviously enhances the porosity and the specific surface area.

To obtain detailed chemical surface information, we conducted XPS measurement on the 
$\mathrm{BiVO}_{4}$ samples, which are presented in the supplementary material in Fig. S1. All the spectral data is consistent with previous research reports [44, 45], suggesting that the prepared $\mathrm{BiVO}_{4}$ film is composed of only $\mathrm{Bi}, \mathrm{V}$, and $\mathrm{O}$ without any detectable impurities.

The UV-visible (UV-Vis) absorption spectrum of $\mathrm{BiVO}_{4}$ electrode is shown in the Fig. 3. It can be seen that the $\mathrm{BiVO}_{4}$ sample exhibits a clear absorption edge at about $500 \mathrm{~nm}$, corresponding to the visible light region. This indicates that $\mathrm{BiVO}_{4}$ can efficiently absorb visible light, which is consistent with the yellow color of the electrode (lower-left inset in Fig. 3). Moreover, the band-gap energy of the prepared $\mathrm{BiVO}_{4}$ sample is determined to be approximately $2.4 \mathrm{eV}$ according to the Tauc equation (upper-right inset in Fig. 3).

\subsection{Photoelectrochemical behavior of $\mathrm{BiVO}_{4}$ electrode}

In order to investigate the photoelectrochemical performance of $\mathrm{BiVO}_{4}$ photoanode, linear sweep voltammetry (LSV) was conducted in $0.5 \mathrm{M}$ phosphate buffer, and the results are presented in Fig. 4a. Under visible light, the current increases with increasing applied potential and reaches $1.45 \mathrm{~mA} \cdot \mathrm{cm}^{-2}$ at $+0.6 \mathrm{~V}$ versus $\mathrm{Ag} / \mathrm{AgCl}$, which is equivalent to $+1.23 \mathrm{~V}$ versus reversible hydrogen electrode (RHE), whereas negligible current is produced in the dark. The inset of Fig. 4a exhibits the transient photocurrent responses measured at $+1.23 \mathrm{~V}$ (vs. RHE) applied potential with chopped illumination in $0.5 \mathrm{M}$ phosphate buffer. A spiculate photocurrent spike is observed immediately when the light is turned on, and it then drops down to a steady photocurrent, which means that the $\mathrm{BiVO}_{4}$ electrode demonstrates a significant response to visible light. The current density of $\mathrm{BiVO}_{4}$ also retains an almost constant value after $400 \mathrm{~s}$, showing excellent photoelectric stability.

A Mott-Schottky experiment was performed to determine the band positions of the $\mathrm{BiVO}_{4}$ sample. The flat band potential is evaluated by the onset potential of the photocurrent, as shown in Fig. 4b. The corresponding flat-band potential value of the as-prepared film is determined by the Mott-Schottky equation [46].

$$
\frac{1}{C^{2}}=\frac{2}{\varepsilon \varepsilon_{0} N_{D}}\left(E-E_{\mathrm{fb}}-\frac{\kappa_{b} T}{q}\right)
$$

where $C=$ space charge capacitance, $\varepsilon=$ dielectric constant, $\varepsilon_{0}=$ vacuum dielectric constant, $N_{\mathrm{D}}=$ donor density, $k_{\mathrm{b}}=$ Boltzmann's constant, $E=$ applied potential, $E_{\mathrm{fb}}=$ flat band potential, and $q=$ 
electronic charge. The flat band potential of $\mathrm{BiVO}_{4}$ is calculated to be $-0.455 \mathrm{~V}$ vs. $\mathrm{Ag} / \mathrm{AgCl}$, (0.156 V vs. RHE). As is well known, the conduction band position of many $n$-type semiconductors is $0-0.1 \mathrm{eV}$ higher than the flat potential. Assuming that the gap between the bottom of the conduction band and the flat potential is $0.05 \mathrm{eV}$, the conduction band position of $\mathrm{BiVO}_{4}$ is determined to be $+0.1 \mathrm{eV}$. Since the band gap of the as-prepared sample is $2.4 \mathrm{eV}$ (inset of Fig. 3), the valence band position is estimated to be $+2.5 \mathrm{eV}$. According to the above-mentioned values, we constructed a schematic diagram of the band positions and the redox potential for $\mathrm{BiVO}_{4}$ film, as shown in the inset of Fig. $4 \mathrm{~b}$, which reveals that the valence band position of $\mathrm{BiVO}_{4}$ is relatively low and that the photogenerated holes with strong oxidizing ability can directly oxidize organic materials adsorbed on the electrode surface.

Electrochemical impedance spectroscopy (EIS) is a useful method to investigate electrochemical behaviour from the aspect of charge transfer. To assess the kinetics of charge transfer in $\mathrm{BiVO}_{4}$ electrode, we conducted EIS measurements in $0.10 \mathrm{M}$ phosphate buffered saline (PBS) in the dark and under illumination, and the corresponding results are shown in Fig. S2. Compared with $\mathrm{BiVO}_{4}$ in the dark, the $\mathrm{BiVO}_{4}$ electrode under illumination exhibits dramatically decreased resistance even without any applied bias (potential $=0 \mathrm{~V}$ ). This indicates that the electrode possesses higher electron-hole separation efficiency and suffers from a lower charge recombination rate under light irradiation [47].

\subsection{Photoelectrochemical oxidation of glucose}

Firstly, the cyclic voltammetry curves $(\mathrm{CVs})$ of $\mathrm{BiVO}_{4}$ electrode for the photoelectrochemical oxidation of glucose were measured in $0.1 \mathrm{M} \mathrm{NaNO}_{3}$ solution under light illumination. As shown in Fig. 5a, a significant oxidation peak is observed at about $+0.15 \mathrm{~V}$ (vs. $\mathrm{Ag} / \mathrm{AgCl}$ ) when the glucose is added to the electrolyte, and the anodic peak current increases with increased glucose concentration, which suggests that the $\mathrm{BiVO}_{4}$ electrode exhibits a good response to glucose at $+0.15 \mathrm{~V}$ under visible light irradiation. Furthermore, the $\mathrm{CVs}$ of $\mathrm{BiVO}_{4}$ electrode with different concentrations of glucose in the dark are almost negligible compared with that of under light illumination (Fig. S3). Therefore, we set the bias potential at $+0.15 \mathrm{~V}$ (vs. $\mathrm{Ag} / \mathrm{AgCl}$ ) for all subsequent experiments. The effect of the potential scan rate on electron transfer between glucose and the surface of the $\mathrm{BiVO}_{4}$ electrode was also investigated in $0.1 \mathrm{M} \mathrm{NaNO}_{3}$ with $2 \mathrm{mM}$ glucose. 
As shown in Fig. S4, the anodic peak current linearly increases with increasing scan rate, indicating that the oxidation of glucose on the $\mathrm{BiVO}_{4}$ electrode is a surface controlled photoelectrochemical process.

Fig. $5 \mathrm{~b}$ presents a typical photocurrent response of $\mathrm{BiVO}_{4}$ electrode with and without glucose at an applied potential of $0.15 \mathrm{~V}$ (vs. $\mathrm{Ag} / \mathrm{AgCl})$ under visible light illumination. It can be observed that the photocurrent decreases rapidly and then settles on a steady value. For the blank sample without glucose, the steady photocurrent $\left(I_{b l a n k}\right)$ results from the oxidation of water. Meanwhile, the total photocurrent in the steady state $\left(I_{\text {total }}\right)$ in the presence of glucose can be divided into two parts: one arises from the oxidation of water $\left(I_{\text {blank }}\right)$ and the other is due to the oxidation of glucose ( $I_{n e t}$ [48]. Therefore, the $I_{\text {net }}$ can be calculated by subtracting $I_{\text {blank }}$ from $I_{\text {total }}$ (see Eq. (2)).

$$
I_{\text {net }}=I_{\text {total }}-I_{\text {blank }}
$$

Based on the above discussion, the initial photocurrent is caused by the oxidation of pre-adsorbed glucose molecules. As the dark processing time increases, the total amount of transferred electrons $\left(Q_{n e t}\right)$ resulting from the degradation of glucose molecules adsorbed on the $\mathrm{BiVO}_{4}$ electrode increases and reaches a maximum at a certain time, as shown in Fig. 6a. The in-situ adsorption measurement of glucose illustrated in Fig. $6 \mathrm{~b}$ also indicates that the adsorption process reaches a maximum for all concentrations from $100 \mu \mathrm{M}$ to $2 \mathrm{mM}$ after $2 \mathrm{~min}$. As known, the adsorption behavior of organic compounds on the surfaces of metal oxides commonly follows the Langmuir adsorption model $[49,50]$. Assuming monolayer adsorption, the Langmuir isotherm equation can be written as:

$$
\frac{C}{Q_{\text {net }}}=\frac{1}{Q_{\max }} C+\frac{1}{K Q_{\max }}
$$

Where $C$ is the equilibrium bulk concentration of adsorbate, $Q_{\text {net }}$ is the net charge resulting from the oxidation of adsorbate, $Q_{\max }$ represents the maximum net charge for $100 \%$ surface coverage, and $K$ denotes the adsorption equilibrium constant. The experimental data obtained in Fig. $6 \mathrm{~b}$ was used to fit with the Langmuir model by plotting $C / Q_{\text {net }}$ against $C$. A straight line was then obtained as shown in Fig. 6c. This result indicates that the adsorption of glucose on the surface of $\mathrm{BiVO}_{4}$ agrees well with the classical Langmuir adsorption model, where the glucose molecules form a monolayer covering the surface of the $\mathrm{BiVO}_{4}$ electrode. 


\subsection{Detection of glucose}

Previous research demonstrates that the thickness of the $\mathrm{BiVO}_{4}$ film has a great influence on the initial photocurrent and sensitivity of the electrode [51]. Therefore, the thickness of $\mathrm{BiVO}_{4}$ film was optimized by investigating samples with different deposition times. As shown in Fig. S5, with increasing deposition time, the thickness of the film linearly increases, and the initial photocurrent yields an optimum response at around $390 \mathrm{~s}$. The reason is that the response current density is primarily dominated by light absorbance when the deposition time is less than $390 \mathrm{~s}$. Deposition times over $390 \mathrm{~s}$ will generate thick films that are not favorable for the transfer of charge carriers. Thus, $390 \mathrm{~s}$ was used in the deposition of $\mathrm{BiVO}_{4}$ in further experiments.

The effect of light intensity on the photocurrent response of $\mathrm{BiVO}_{4}$ electrode was also investigated by linear sweep voltammetry (LSV). In this study, the light intensity was adjusted by changing the distance between the electrolytic cell and the lamp. As demonstrated in Fig. S6a, with increasing light intensity, the photocurrent increases, although the shape of the anode LSV curves is not change. The influence of light intensity on the photocurrent under a constant potential was also investigated (Fig. S6b). Clearly, the current density measured at $0.6 \mathrm{~V}$ vs. $\mathrm{Ag} / \mathrm{AgCl}$ increases as the light intensity increases from 0 to $100 \mathrm{~mW} / \mathrm{cm}^{2}$, and it displays a nearly linear correlation with light intensity.

Under the optimized experimental conditions, a time-dependent PEC photocurrent $(i-t)$ measurement of the $\mathrm{BiVO}_{4}$ electrode upon successive addition of glucose to $0.1 \mathrm{M} \mathrm{NaNO}_{3}$ was carried out at an applied potential of $0.15 \mathrm{~V}$. As shown in Fig. 7a, the photocurrent of the $\mathrm{BiVO}_{4}$ electrode increases upon each addition of glucose, and rapidly reaches a new steady-state, suggesting that the as-prepared electrode exhibits an excellent response to the changing glucose concentration with a rapid oxidation process. Meanwhile, the calibration curve for $\mathrm{BiVO}_{4}$ based PEC glucose sensor is worked out, as presented in Fig. 7b. The proposed glucose sensor displays an excellent linear range from 0 to $5 \mathrm{mM}$ with a correlation coefficient $(R)$ of 0.997 (inset in Fig. 7b), and the detection limit is $0.13 \mu \mathrm{M}$ (signal to noise, $\mathrm{S} / \mathrm{N}=3$ ), which allow $\mathrm{BiVO}_{4}$ to serve as a visible-light photoelectrochemical material with high sensitivity for the sensing of glucose. Additionally, the error bars, which represent standard deviations for five separate 
measurements at each glucose concentration, indicate good repeatability of the $\mathrm{BiVO}_{4}$ electrode in detecting glucose.

\subsection{Selectivity, reproducibility, and stability}

It is well known that ascorbic acid (AA), dopamine (DA) and uric acid (UA) are common interfering species for glucose detection [52-54]. Thus, in order to better evaluate the selectivity of the BiVO4 sensor, interference tests were conducted in $2 \mathrm{mM}$ glucose solution containing $10 \mathrm{mM}$ AA, DA, or UA, which are 5 times more concentrated than glucose. As shown in Fig. 8a, none of these interfering substances cause any observable change in the photocurrent for the proposed PEC sensor. According to the Ref. [55], the content of glucose in human serum is about 30 times that of AA or DA at normal physiological levels. Therefore, the sensor based on $\mathrm{BiVO}_{4}$ has good selectivity toward glucose.

The reproducibility of the PEC sensor was investigated by measuring the current responses of ten independently prepared $\mathrm{BiVO}_{4}$ electrodes toward $2 \mathrm{mM}$ of glucose solution. As shown in Fig. $8 \mathrm{~b}$, the relative standard deviation (RSD) is $2.21 \%$, suggesting excellent reproducibility. The $\mathrm{BiVO}_{4}$ electrodes were also used to test for $2 \mathrm{mM}$ glucose five times, and the RSD was lower than $2.0 \%$, indicating a good repeatability. To verify the stability of the proposed glucose sensor, time-dependent photocurrent $(i-t)$ measurements were conducted at several representative glucose concentrations from 0 to $4 \mathrm{mM}$ at $1.5 \mathrm{~V}$ vs. $\mathrm{Ag} / \mathrm{AgCl}$ (Fig. $8 \mathrm{c}$ ). It was found that the current response to each glucose concentration is highly stable and well-consistent with the repeated light on-off cycles. The sensor was stored at room temperature, and its long-term stability was evaluated by testing the current response of the $\mathrm{BiVO}_{4}$ film electrode to $2 \mathrm{mM}$ glucose over 30 days. According to the results in Fig. 8d, the electrode maintained about $91 \%$ of the initial detection signals even after 30 days, which implies the good stability of the PEC sensor.

\subsection{Human serum sample measurements}

To investigate the practicability of the PEC glucose sensor, the $\mathrm{BiVO}_{4}$ modified electrode was utilized for glucose detection in real blood serum samples. The human serum samples were diluted by 100 fold with $0.1 \mathrm{M} \mathrm{NaNO}_{3}$ solution before measurements and the results are shown in Table 1. It should be noted that the determined glucose concentrations are all similar to the values measured by the hospital. Also, the RSD of the PEC glucose sensor is below 7\% even at 
low concentrations, suggesting that the electrode can be practically employed to detect glucose in real serum samples.

Table 1 Detection of glucose in human serum samples.

\begin{tabular}{ccccc}
\hline Sample & $\begin{array}{l}\text { Concentration } \\
\text { measured by } \\
\text { hospital }(\mathrm{mM})\end{array}$ & $\begin{array}{l}\text { Concentration } \\
\text { measured by the } \\
\text { PEC sensor }(\mathrm{mM})\end{array}$ & $\begin{array}{c}\text { Recovery } \\
(\%)\end{array}$ & $\begin{array}{c}\text { RSD (\%) } \\
(\mathrm{n}=5)\end{array}$ \\
\hline 1 & 4.8 & 4.94 & 102.9 & 5.5 \\
2 & 5.1 & 4.99 & 97.8 & 6.9 \\
3 & 5.6 & 5.46 & 97.5 & 4.1 \\
\hline
\end{tabular}

\section{Conclusion}

In conclusion, a non-enzymatic PEC glucose sensor based on $\mathrm{BiVO}_{4}$ electrode was successfully fabricated. The adsorption of glucose on the surface of $\mathrm{BiVO}_{4}$ agrees well with the classical Langmuir adsorption model. The sensor based on $\mathrm{BiVO}_{4}$ electrode can realize the PEC oxidation of glucose under visible-light irradiation with an outstanding photocurrent response. In the range of $0-5 \mathrm{mM}$, a good linear relationship between glucose concentration and current value has been established. Furthermore, the sensor exhibited a high selectivity against several tested common interfering substances in glucose detection. Additionally, the proposed sensor detected glucose in human serum samples. This work not only has developed a photoelectrochemical glucose sensor based on $\mathrm{BiVO}_{4}$ electrode under visible light, but also has demonstrated the bright prospects for the PEC sensor in organic matter detection.

\section{Acknowledgements}

The authors are grateful for financial support from the National Natural Science Foundation of China (Grant Nos.51672018, 51472016, 11874003), Beijing Natural Science Foundation (Grant No. Z180007) and Fundamental Research Fund for Centre University. H. F. F. and Y. D. thank the Australian Research Council (ARC) for partial support of this work through a Discovery Project (DP140102581, DP170101467). Thank Xuanwu Hospital Capital Medical University for the support of human serum samples. Thanks for the guidance of Biological procedures from Institute of Zoology, Chinese Academy of Sciences. 


\section{References}

[1] J. Wang, Electrochemical glucose biosensors, Chem. Rev. 108 (2008) 814-825.

[2] N.H. Cho, J.E. Shaw, S. Karuranga, Y. Huang, J.D.D.R. Fernandes, A.W. Ohlrogge, B.Malanda, IDF Diabetes Atlas: Global estimates of diabetes prevalence for 2017 and projections for 2045, Diabetes Res. Clin. Pract. 138 (2018) 271 .

[3] S.A. Shabbir, S. Shamaila, N. Zafar, A. Bokhari, A. Sabah, Nonenzymatic glucose sensor with high performance electrodeposited nickel/copper/carbon nanotubes nanocomposite electrode, J. Phys. Chem. Solids 120 (2018) 12-19.

[4] J. Lee, S. Ko, C.H. Kwon, M.D. Lima, R.H. Baughman, S.J. Kim, Carbon nanotube yarn-based glucose sensing artificial muscle, Small 12 (2016) 2085-2091.

[5] E.B. Bahadir, M.K. Sezginturk, Applications of commercial biosensors in clinical, food, environmental and biothreat/biowarfare analyses, Anal. Biochem. 478 (2015) 107-120.

[6] F. Yang, X. Yang, Z. Cao, S. Chen, B. Zhu, Synthesis of mesoporous CuO microspheres with core-in-hollow-shell structure and its application for non-enzymatic sensing of glucose, J. Appl. Electrochem. 45 (2015) 131-8.

[7] G. Wang, X. Lu, T. Zhai, Y. Ling, H. Wang, Y. Tong, et al., Free-standing nickel oxide nanoflake arrays: synthesis and application for highly sensitive non-enzymatic glucose sensors, Nanoscale 4 (2012) 3123-7.

[8] H. Wu, G. Das, H.H. Yoon, Fabrication of an amperometric urea biosensor using urease and metal catalysts immobilized by a polyion complex, J. Electroanal. Chem. 747 (2015) 143-8.

[9] A. Heller, B. Feldman, Electrochemical glucose sensors and their application in diabetes management, Chem. Rev. 108 (2008) 2482-2505.

[10] B.L.Clark, C.R, Lyons, Electrode systems for continuous monitoring in cardiovascular surgery, Ann. N.Y. Acad. Sci. 102 (2010) 29-45.

[11] C. Xia, W. Ning, A novel non-enzymatic electrochemical glucose sensor modified with FeOOH nanowire, Electrochem. Commun. 12 (2010) 1581-1584.

[12] S. Nantaphol, T. Watanabe, N. Nomura, W. Siangproh, O. Chailapakul, Y. Einaga, Bimetallic Pt-Au nanocatalysts electrochemically deposited on boron-doped diamond electrodes for nonenzymatic glucose detection, Biosens. Bioelectron. 98 (2017) 76-82.

[13] L. Luo, F. Li, L. Zhu, Y. Ding, Z. Zhang, D. Deng, B. Lu, Nonenzymatic glucose sensor based on 
nickel(II)oxide/ordered mesoporous carbon modified glassy carbon electrode, Colloid Surf. B-Biointerfaces 102 (2013) 307-311.

[14] T. Choi, S.H. Kim, C.W. Lee, H. Kim, S.K. Choi, S.H. Kim, E. Kim, J. Park, H. Kim, Synthesis of carbon nanotube-nickel nanocomposites using atomic layer deposition for high-performance non-enzymatic glucose sensing, Biosens. Bioelectron. 63 (2015) 325-330.

[15] H. Lee, T.K. Choi, Y.B. Lee, H.R. Cho, R. Ghaffari, L. Wang, H.J. Choi, T.D. Chung, N. Lu, T. Hyeon, A graphene-based electrochemical device with thermoresponsive microneedles for diabetes monitoring and therapy, Nat. Nanotechnol. 11 (2016) 566-572.

[16] S.K. Meher, G.R. Rao, Archetypal sandwich-structured $\mathrm{CuO}$ for high performance non-enzymatic sensing of glucose, Nanoscale 5 (2013) 2089-2099.

[17] P. Lu, Q. Liu, Y. Xiong, Q. Wang, Y. Lei, S. Lu, L. Lu, L. Yao, Nanosheets-assembled hierarchical microstructured $\mathrm{Ni}(\mathrm{OH})_{2}$ hollow spheres for highly sensitive enzyme-free glucose sensors, Electrochim. Acta 168 (2015) 148-156.

[18] L. Han, S. Zhang, L. Han, D.P. Yang, C. Hou, A. Liu, Porous gold cluster film prepared from Au@BSA microspheres for electrochemical nonenzymatic glucose sensor, Electrochim. Acta 138 (2014) 109-114.

[19] Z. Wei-Wei, X. Jing-Juan, C. Hong-Yuan, Photoelectrochemical DNA biosensors, Chem. Rev. 114 (2014) 7421.

[20] Z. Wei-Wei, X. Jing-Juan, C. Hong-Yuan, Photoelectrochemical bioanalysis: The state of the art, Chem. Soc. Rev. 44 (2015) 729-41.

[21] W.W. Zhao, J.J. Xu, H.Y. Chen, Photoelectrochemical aptasensing, Trac-Trends Anal. Chem. 82 (2016) $307-15$.

[22] X. Zhang, Y. Guo, M. Liu, S. Zhang, Photoelectrochemically active species and photoelectrochemical biosensors, RSC Adv. 3 (2013) 2846-2857.

[23] Y. Zhang, B. Tang, Z. Wu, H. Shi, Y. Zhang, G. Zhao, Glucose oxidation over ultrathin carbon-coated perovskite modified $\mathrm{TiO}_{2}$ nanotube photonic crystals with high-efficiency electron generation and transfer for photoelectrocatalytic hydrogen production, Green Chem. 18 (2015) 2424-2434.

[24] Y. Wang, L. Bai, Y. Wang, D. Qin, D. Shan, X. Lu, Ternary nanocomposites of $\mathrm{Au} / \mathrm{CuS} / \mathrm{TiO}_{2}$ for an ultrasensitive photoelectrochemical non-enzymatic glucose sensor, Analyst 143 (2018) 1699-1704.

[25] Y. Wang, W. Wang, S. Wang, W. Chu, T. Wei, H. Tao, et al., Enhanced photoelectrochemical detection of 1 -cysteine based on the ultrathin polythiophene layer sensitized anatase $\mathrm{TiO}_{2}$ on F-doped tin oxide substrates, Sens. 
Actuator. B-Chem. 232 (2016) 448-53.

[26] Y. Yan, Q. Liu, X. Du, J. Qian, H. Mao, K. Wang, Visible light photoelectrochemical sensor for ultrasensitive determination of dopamine based on synergistic effect of graphene quantum dots and $\mathrm{TiO}_{2}$ nanoparticles, Anal. Chim. Acta 853(2015) 258-64.

[27] H. Wang, Y. Zhang, H. Li, B. Du, H. Ma, D. Wu, et al., A silver-palladium alloy nanoparticle-based electrochemical biosensor for simultaneous detection of ractopamine, clenbuterol and salbutamol, Biosens. Bioelectron. 49 (2013) 14-9.

[28] S. Komathi, N. Muthuchamy, K.P. Lee, A.I. Gopalan, Fabrication of a novel dual mode cholesterol biosensor using titanium dioxide nanowire bridged 3D graphene nanostacks, Biosens. Bioelectron. 84 (2016) 64-71.

[29] X. Wang, D. Liao, H. Yu, J. Yu, Highly efficient $\mathrm{BiVO}_{4}$ single-crystal photocatalyst with selective $\mathrm{Ag}_{2} \mathrm{O}-\mathrm{Ag}$ modification: orientation transport, rapid interfacial transfer and catalytic reaction, Dalton Trans. 47 (2018) 6370-6377.

[30] J. Fang, L. Xu, Z. Zhang, Y. Yuan, S. Cao, Z. Wang, et al., Au@ $\mathrm{TiO}_{2}-\mathrm{CdS}$ ternary nanostructures for efficient visible-light-driven hydrogen generation, ACS Appl. Mater. Interfaces 5 (2013) 8088-92.

[31] G. Ming, Y. Li, L. Lu, Z. Zhen, C. Wei, $\mathrm{Bi}_{2} \mathrm{O}_{3}-\mathrm{Bi}_{2} \mathrm{WO}_{6}$ Composite Microspheres: Hydrothermal synthesis and photocatalytic performances, J. Phys. Chem. C 115 (2011) 5220-5225.

[32] T.W. Kim, K.S. Choi, Nanoporous $\mathrm{BiVO}_{4}$ photoanodes with dual-layer oxygen evolution catalysts for solar water splitting, Science 45 (2014) 990-994.

[33] Y. Chen, G. Tian, Y. Shi, Y. Xiao, H. Fu, Hierarchical $\mathrm{MoS}_{2} / \mathrm{Bi}_{2} \mathrm{MoO}{ }_{6}$ composites with synergistic effect for enhanced visible photocatalytic activity, Appl. Catal. B 164 (2015) 40-47.

[34] Z. Lin, W. Wenzhong, X. Haolan, S. Songmei, S. Meng, $\mathrm{Bi}_{2} \mathrm{O}_{3}$ hierarchical nanostructures: controllable synthesis, growth mechanism, and their application in photocatalysis, Chem.: Eur. J 15 (2009) 1776-1782.

[35] S.K. Pilli, T.E. Furtak, L.D. Brown, T.G. Deutsch, J.A. Turner, A.M. Herring, Cobalt-phosphate (Co-Pi) catalyst modified Mo-doped $\mathrm{BiVO}_{4}$ photoelectrodes for solar water oxidation, Energy Environ. Sci. 4 (2011) 5028-5034.

[36] G. Mei-Li, M. De-Kun, H. Sheng-Wei, C. Yan-Jun, H. Shao-Ming, From hollow olive-shaped BiVO to n-p core-shell $\mathrm{BiVO}_{4} @ \mathrm{Bi}_{2} \mathrm{O}_{3}$ microspheres: controlled synthesis and enhanced visible-light-responsive photocatalytic properties, Inorg. Chem. 50 (2011) 800-805.

[37] O.F. Lopes, K.T.G. Carvalho, A.E. Nogueira, W.A. Jr, C. Ribeiro, Controlled Synthesis of $\mathrm{BiVO}_{4}$ Photocatalysts: Evidence of the role of heterojunctions in their catalytic performance driven by visible-light, Appl. 
Catal. B 188 (2016) 87-97.

[38] J. Li, Z. Wei, G. Yang, Z. Wei, M. Han, H. He, et al., Facile synthesis and high activity of novel $\mathrm{BiVO}_{4}$ $/ \mathrm{FeVO}_{4}$ heterojunction photocatalyst for degradation of metronidazole, Appl. Surf. Sci. 351 (2015) 270-279.

[39] H.N. Yun, A. Iwase, A. Kudo, R. Amal, Reducing graphene oxide on a visible-light $\mathrm{BiVO}_{4}$ photocatalyst for an enhanced photoelectrochemical water splitting, J. Phys. Chem. Lett. 1 (2010) 2607-2612.

[40] T. Saison, N. Chemin, C. ChanéAc, O. Durupthy, V.R. Ruaux, L. Mariey, et al., $\mathrm{Bi}_{2} \mathrm{O}_{3}, \mathrm{BiVO}_{4}$, and $\mathrm{Bi}_{2} \mathrm{WO}_{6}$ : impact of surface properties on photocatalytic activity under visible light, J. Phys. Chem. C 115 (2011) 5657-5666. [41] Z.F. Xu, X. Kang, H.F. Feng, D. Yi, W.C. Hao, s-p orbital hybridization: a strategy for developing efficient photocatalysts with high carrier mobility, Sci. Bull. 63 (2018) 465-468.

[42] J. Qingxin, I. Katsuya, K. Akihiko, Facile fabrication of an efficient $\mathrm{BiVO}_{4}$ thin film electrode for water splitting under visible light irradiation, Proc. Natl. Acad. Sci. U.S.A. 109 (2012) 11564-9.

[43] M. Huang, C. Li, L. Zhang, Q. Chen, Z. Zhen, Z. Li, et al., Twin structure in $\mathrm{BiVO}_{4}$ photoanodes boosting water oxidation performance through enhanced charge separation and transport, Adv. Energy Mater. 8 (2018) 1802198.

[44] L. Zhang, A. Dairong Chen, X. Jiao, Monoclinic Structured $\mathrm{BiVO}_{4}$ Nanosheets: Hydrothermal preparation, formation mechanism, and coloristic and photocatalytic properties, J. Phys. Chem. B 110 (2006) 2668-2673.

[45] X.X. Zou, G.D. Li, J. Zhao, P.P. Wang, Y.N. Wang, L.J. Zhou, J. Su, L. Li, J.S. Chen, Light-driven transformation of $\mathrm{ZnS}$-cyclohexylamine nanocomposite into zinc hydroxysulfate: A photochemical route to inorganic nanosheets, Inorg. Chem. 50 (2011) 9106-9113.

[46] J. Shang, W. Hao, X. Lv, T. Wang, X. Wang, Y. Du, S. Dou, T. Xie, D. Wang, J. Wang, Bismuth oxybromide with reasonable photocatalytic reduction activity under visible light, ACS Catal. 4 (2014) 954-961.

[47] Y. Liu, Y.X. Yu, W.D. Zhang, Carbon quantum dots-doped CdS microspheres with enhanced photocatalytic performance, J. Alloy. Compd. 569 (2013) 102-110.

[48] S. Zhang, W. Wen, H. Zhang, H. Zhao, In situ photoelectrochemical measurement of phthalic acid on titania, J. Photochem. Photobiol. A-Chem. 208 (2009) 97-103.

[49] D. Jiang, H. Zhao, S. Zhang, R. John, G.D. Will, Photoelectrochemical measurement of phthalic acid adsorption on porous $\mathrm{TiO}_{2}$ film electrodes, J. Photochem. Photobiol. A-Chem. 156 (2003) 201-206.

[50] S. Muralikrishna, K. Sureshkumar, Z. Yan, C. Fernandez, T. Ramakrishnappa, S. Muralikrishna, K. Sureshkumar, Z. Yan, C. Fernandez, T. Ramakrishnappa, Non-enzymatic amperometric determination of glucose by $\mathrm{CuO}$ nanobelt graphene composite modified glassy carbon electrode, J. Braz. Chem. Soc. 00 (2015) 1-10. 
[51] M. Liu, Y.X. Yu, W.D. Zhang, A Non-enzymatic hydrogen peroxide photoelectrochemical sensor based on a $\mathrm{BiVO}_{4}$ electrode, Electroanalysis 29 (2017) 305- 311.

[52] F. Cao, S. Guo, H. Ma, G. Yang, S. Yang, J. Gong, Highly sensitive nonenzymatic glucose sensor based on electrospun copper oxide-doped nickel oxide composite microfibers, Talanta, 86 (2011) 214-220.

[53] D. Chen, J. Ding, X. Du, Z. Lei, L. Huang, Q. Jing, et al., Engineering efficient charge transfer based on ultrathin graphite-like carbon nitride/ $\mathrm{WO}_{3}$ semiconductor nanoheterostructures for fabrication of high-performances non-enzymatic photoelectrochemical glucose sensor, Electrochim. Acta, 215 (2016) 305-312.

[54] S.A. Shabbir, S. Shamaila, N. Zafar, A. Bokhari, A. Sabah, Nonenzymatic glucose sensor with high performance electrodeposited nickel/copper/carbon nanotubes nanocomposite electrode, J. Phys. Chem. Solids, $120(2018) 12-19$.

[55] F. Cao, S. Guo, H. Ma, G. Yang, S. Yang, J. Gong, Highly sensitive nonenzymatic glucose sensor based on electrospun copper oxide-doped nickel oxide composite microfibers, Talanta 86 (2011) 214-220. 


\section{Figure captions}

Scheme 1 Synthesis process of BiVO4 sensor for glucose detection.

Fig. 1 XRD patterns of the $\mathrm{BiOI}$ and $\mathrm{BiVO}_{4}(*, \mathrm{FTO})$.

Fig. 2 Top view SEM images of (a) BiOI and (b) $\mathrm{BiVO}_{4}$; side view SEM images of (c) $\mathrm{BiOI}$ and (d) $\mathrm{BiVO}_{4}$.

Fig. 3 The UV-Vis spectrum of $\mathrm{BiVO}_{4}$ decorated FTO electrode. The insets show the color and the band-gap value of the film, respectively.

Fig. 4 (a) Photocurrent density-potential curves of $\mathrm{BiVO}_{4}$ electrode in $0.5 \mathrm{M}$ phosphate buffer in the dark and under air mass (AM) 1.5G illumination. The inset shows the photocurrent density-time curve of $\mathrm{BiVO}_{4}$ electrode (0.6 vs. RHE) (b) Mott-Schottky plot for $\mathrm{BiVO}_{4}$ electrode. The inset shows a schematic diagram of the band-gap structure and the redox potential of $\mathrm{BiVO}_{4}$ electrode, with $\mathrm{D}$ representing an organic molecule.

Fig. 5 (a) Continuous cyclic voltammograms $(\mathrm{CVs})$ of $\mathrm{BiOV}_{4}$ electrode in the presence of different concentrations of glucose, collected with a scanning rate of $100 \mathrm{mV} / \mathrm{s}$ in $0.1 \mathrm{M} \mathrm{NaNO}_{3}$ solution under illumination. (b) Typical photocurrent responses of $\mathrm{BiOV}_{4}$ electrode in $0.1 \mathrm{M} \mathrm{NaNO}_{3}$ in the presence (red line) and absence (black line) of glucose. Dark current is shown as a dashed line

Fig. 6 (a) Typical in situ transient photocurrent-time profile for various pre-adsorption times (i.e., dark times) in $0.1 \mathrm{M} \mathrm{NaNO}_{3}$ solution containing $3 \mathrm{mM}$ glucose. (b) The relationship between glucose concentration and $Q_{\text {net }}$ obtained from the in-situ adsorption measurements within a short time scale. (c) The fitting of the isotherm to the Langmuir adsorption model.

Fig. 7 (a) Photocurrent responses of the $\mathrm{BiVO}_{4}$ photoelectrodes in $0.1 \mathrm{M} \mathrm{NaNO}_{3}$ at $+0.15 \mathrm{~V}$ (vs. $\mathrm{Ag} / \mathrm{AgCl}$ ) upon the successive addition of $20 \mu \mathrm{L}$ glucose $(0.3 \mathrm{M})$. (b) Summary of the sensing signal versus glucose concentration. Inset: magnified curve for the low concentration range.

Fig. 8 (a) Effect of interference (AA, DA, and UA) on the response currents. Experiments were performed in 0.1 $\mathrm{M} \mathrm{NaNO}_{3}$ containing $2 \mathrm{mM}$ glucose in the absence and presence of $10 \mathrm{mM}$ AA, DA or UA with light illumination. (b) Photocurrent response of 10 electrodes to $2 \mathrm{mM}$ glucose in $0.1 \mathrm{M} \mathrm{NaNO}_{3}$. (c) Time-dependent photocurrent of $\mathrm{BiVO}_{4}$ electrode at $0.15 \mathrm{~V}$ vs. $\mathrm{Ag} / \mathrm{AgCl}$ over repeated on-off cycles of simulated sunlight illumination. The glucose concentrations are 0-4 mM. (d) Stability test of $\mathrm{BiVO}_{4}$ electrode over a month. 


\section{Scheme 1}

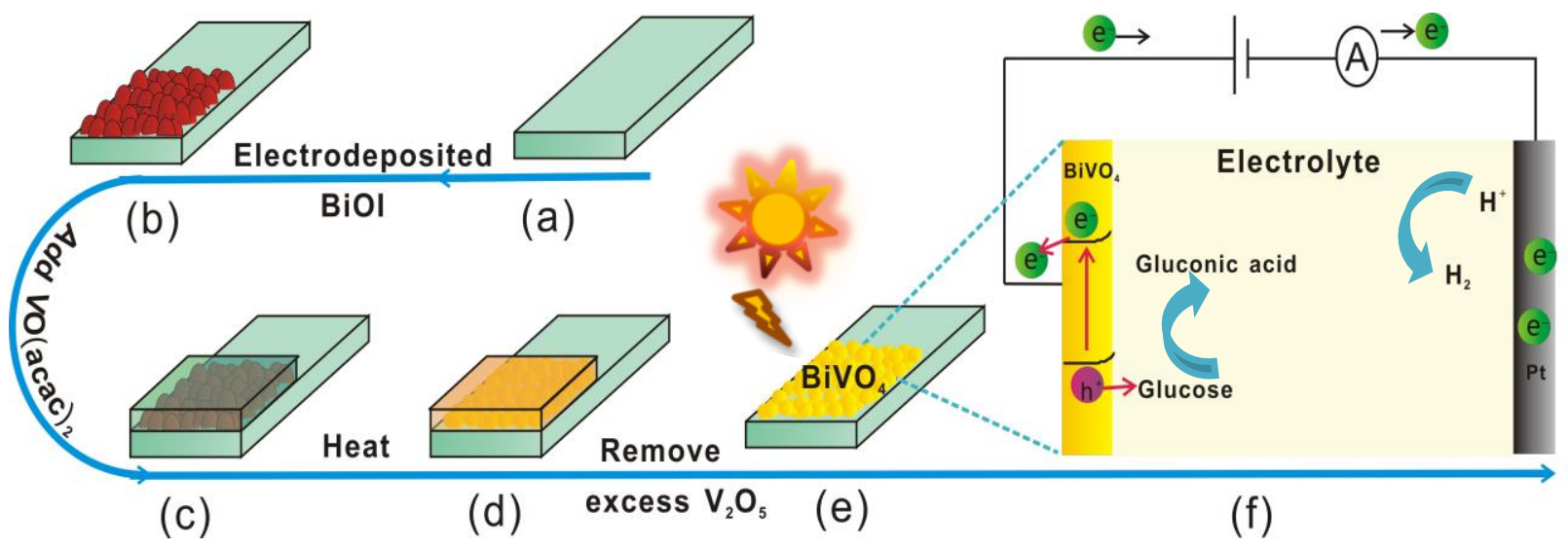


Fig. 1

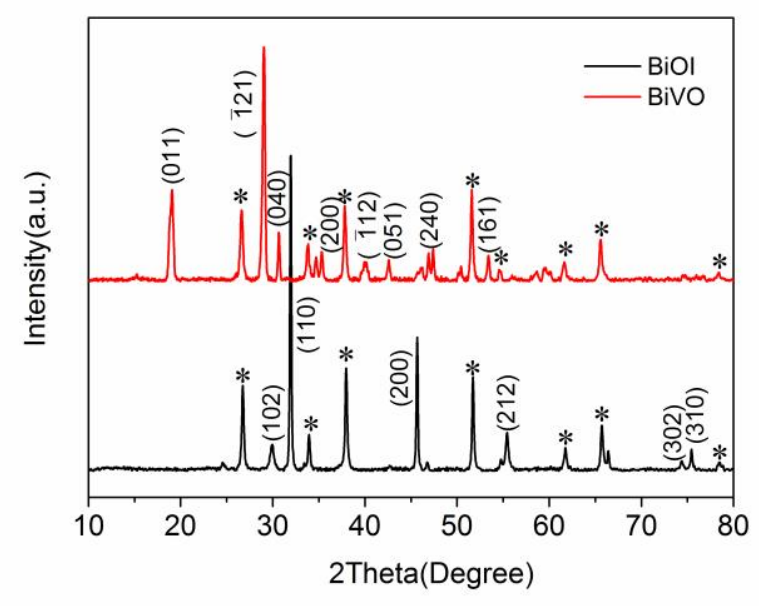


Fig. 2
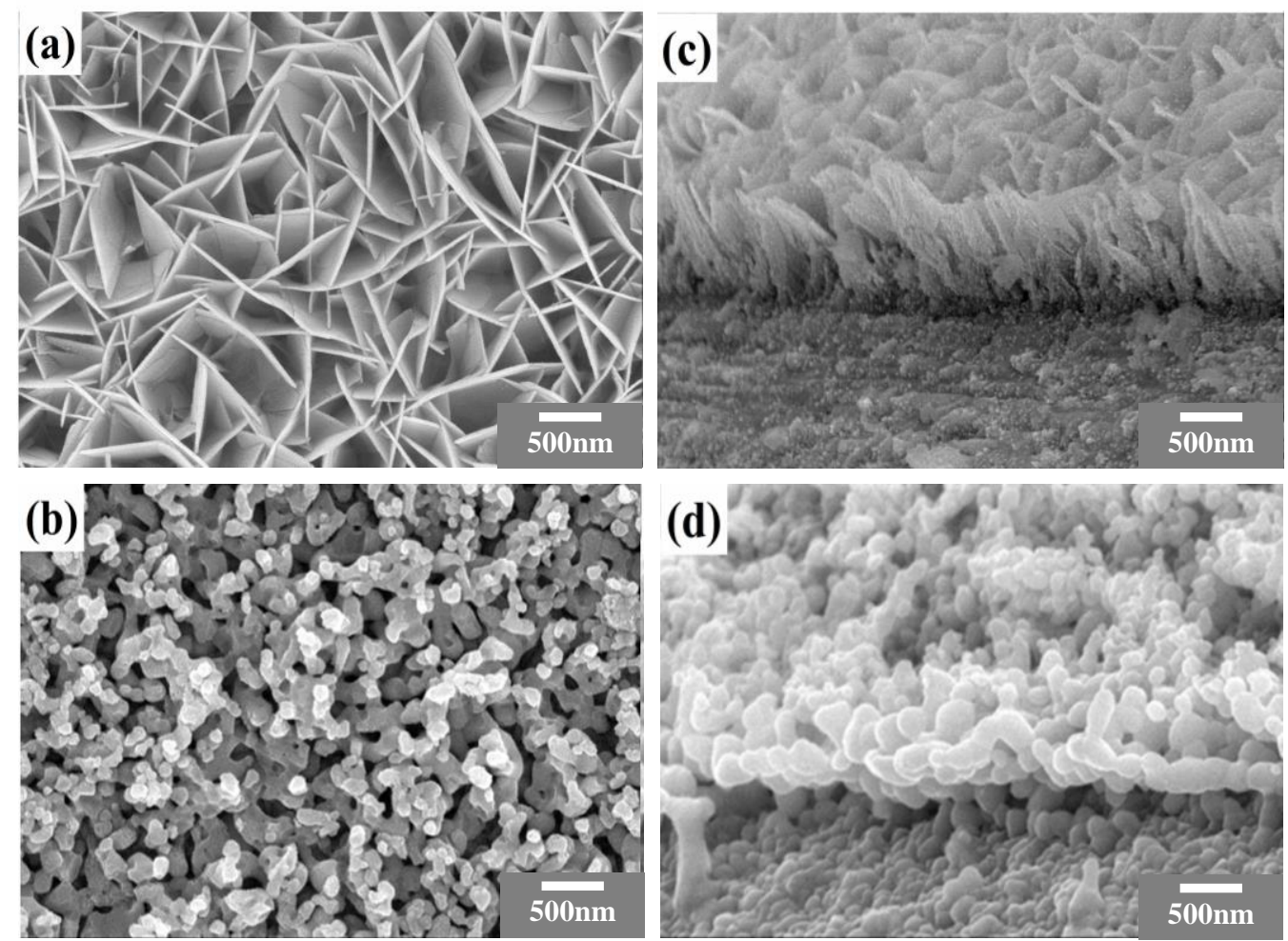
Fig. 3

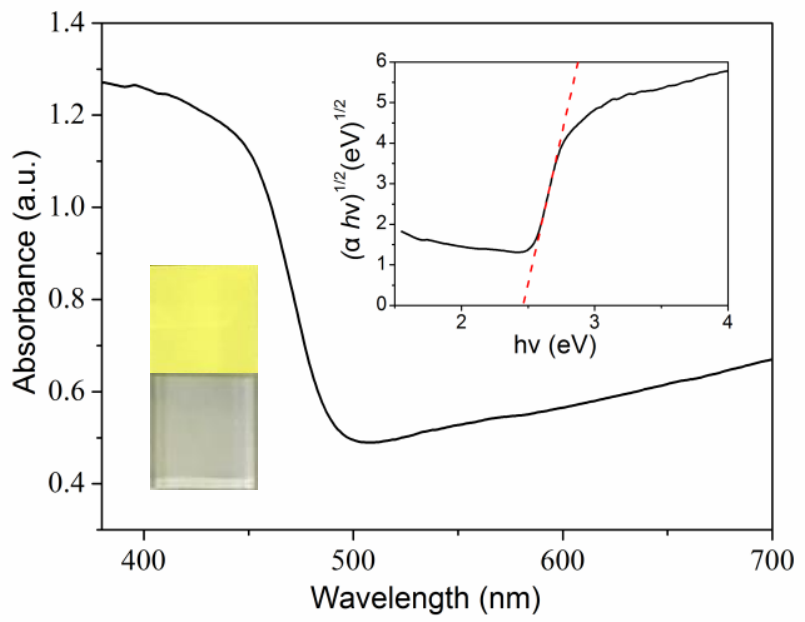


Fig. 4
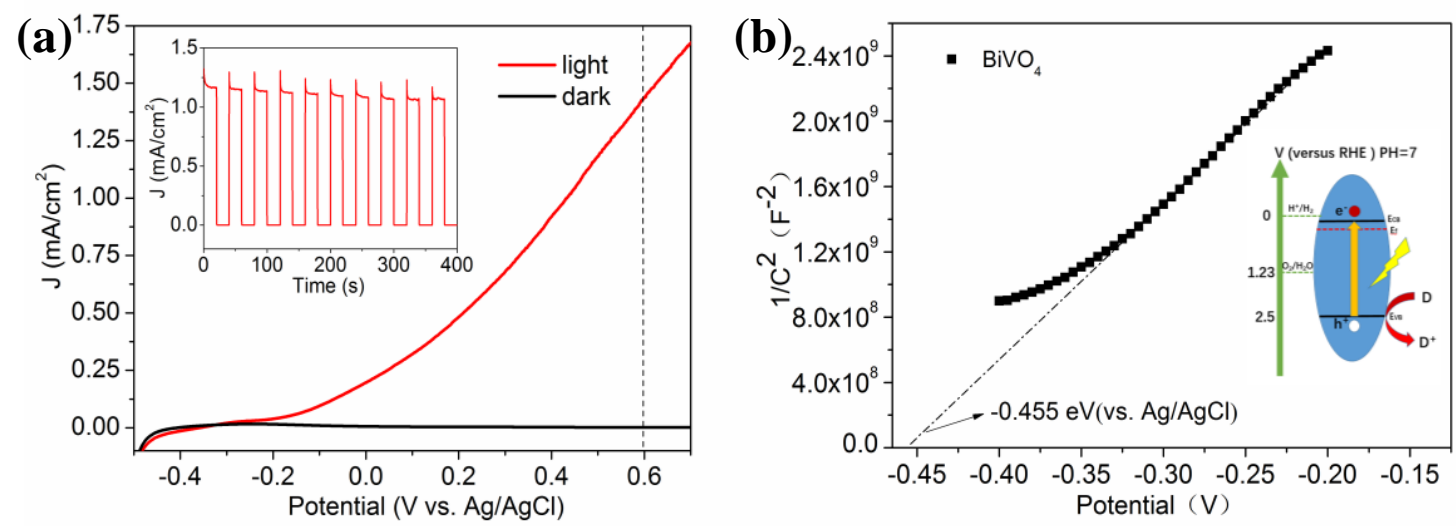
Fig. 5
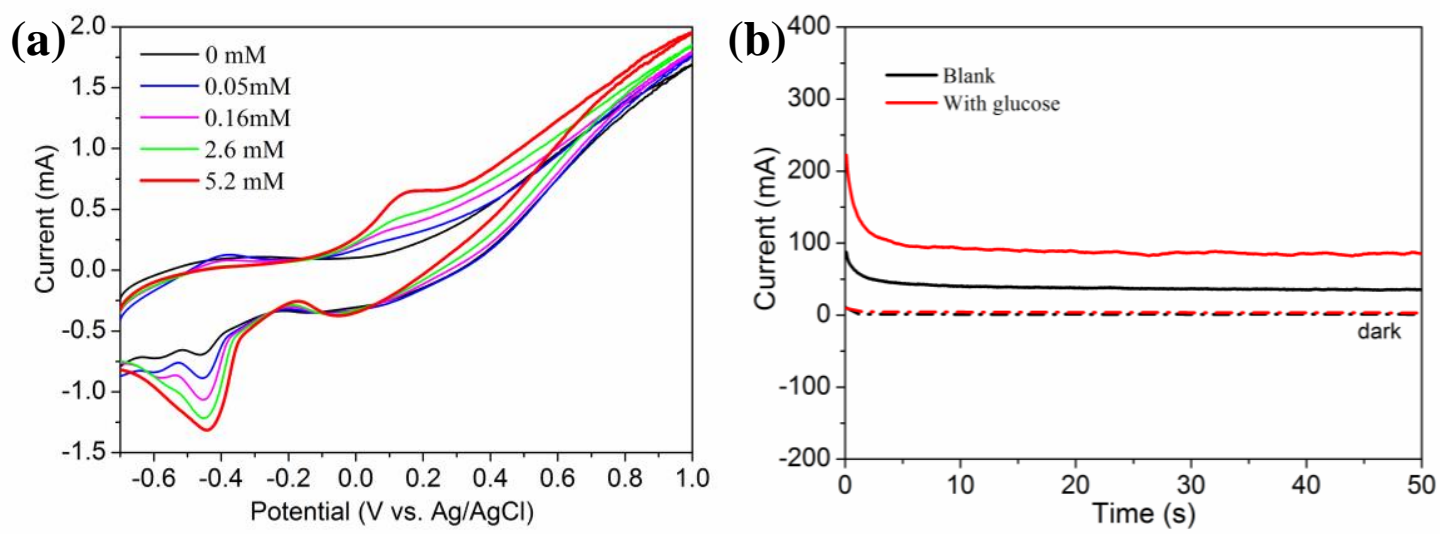
Fig. 6
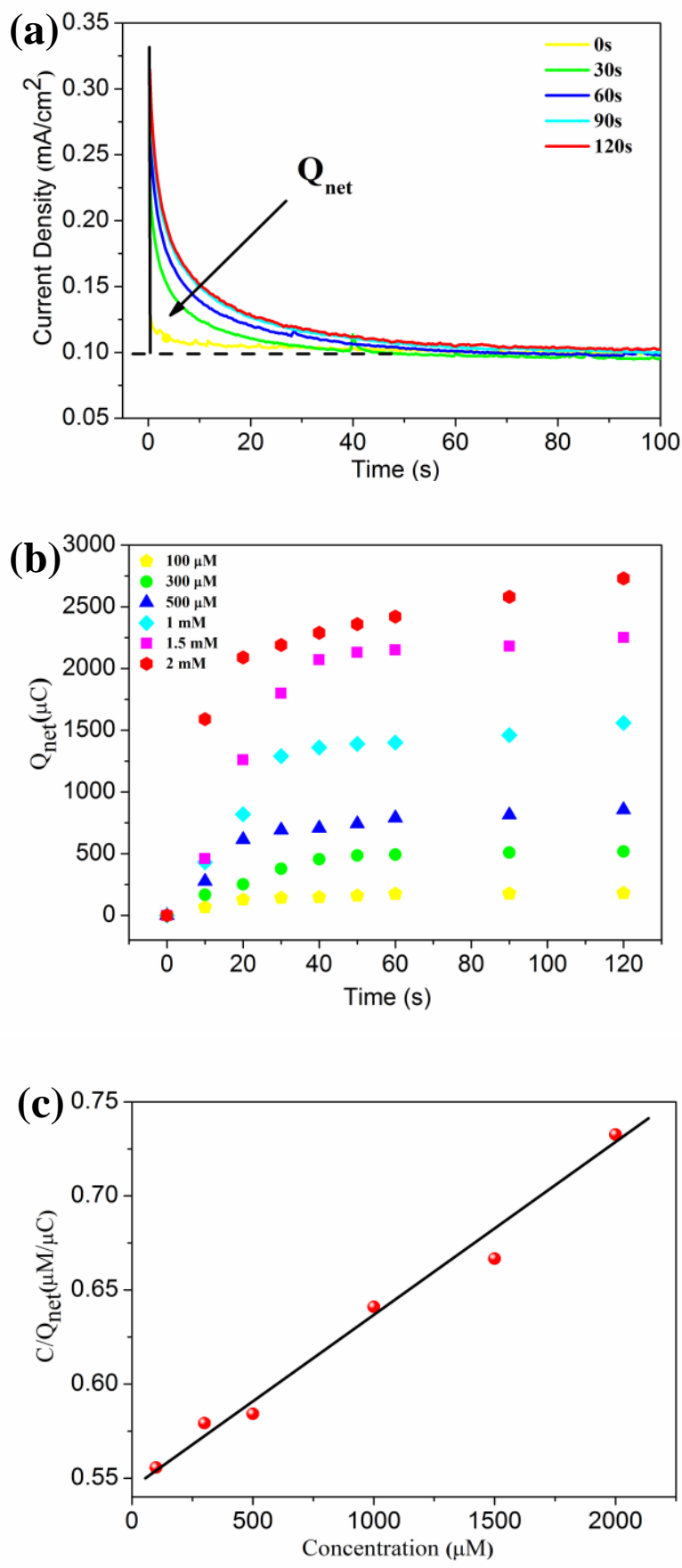
Fig. 7
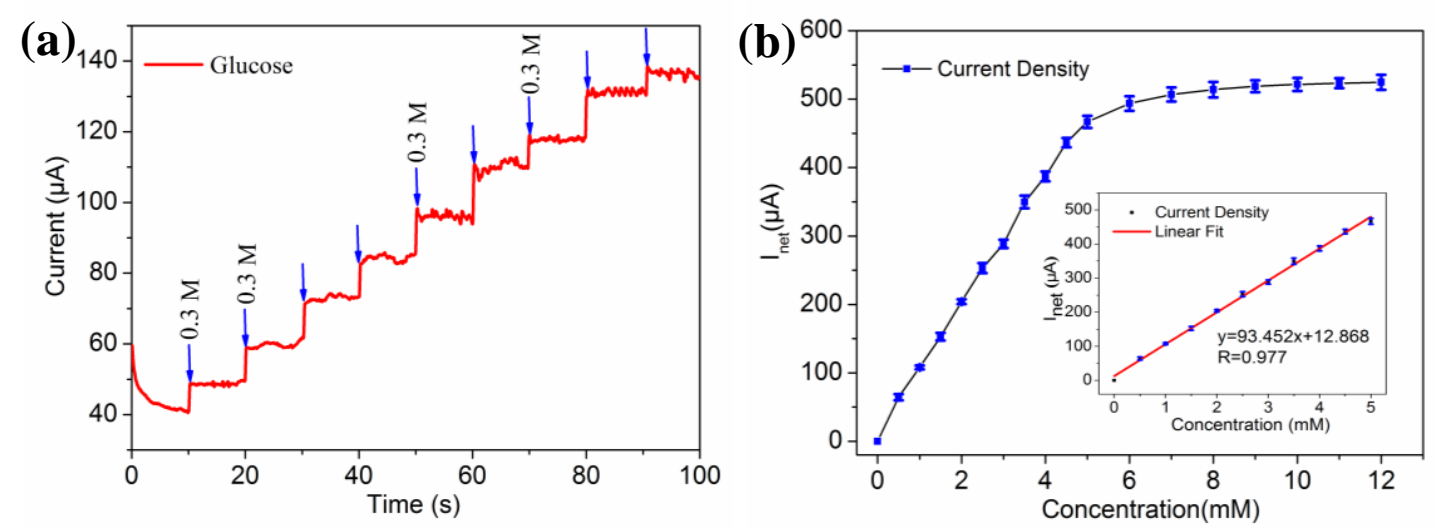
Fig. 8
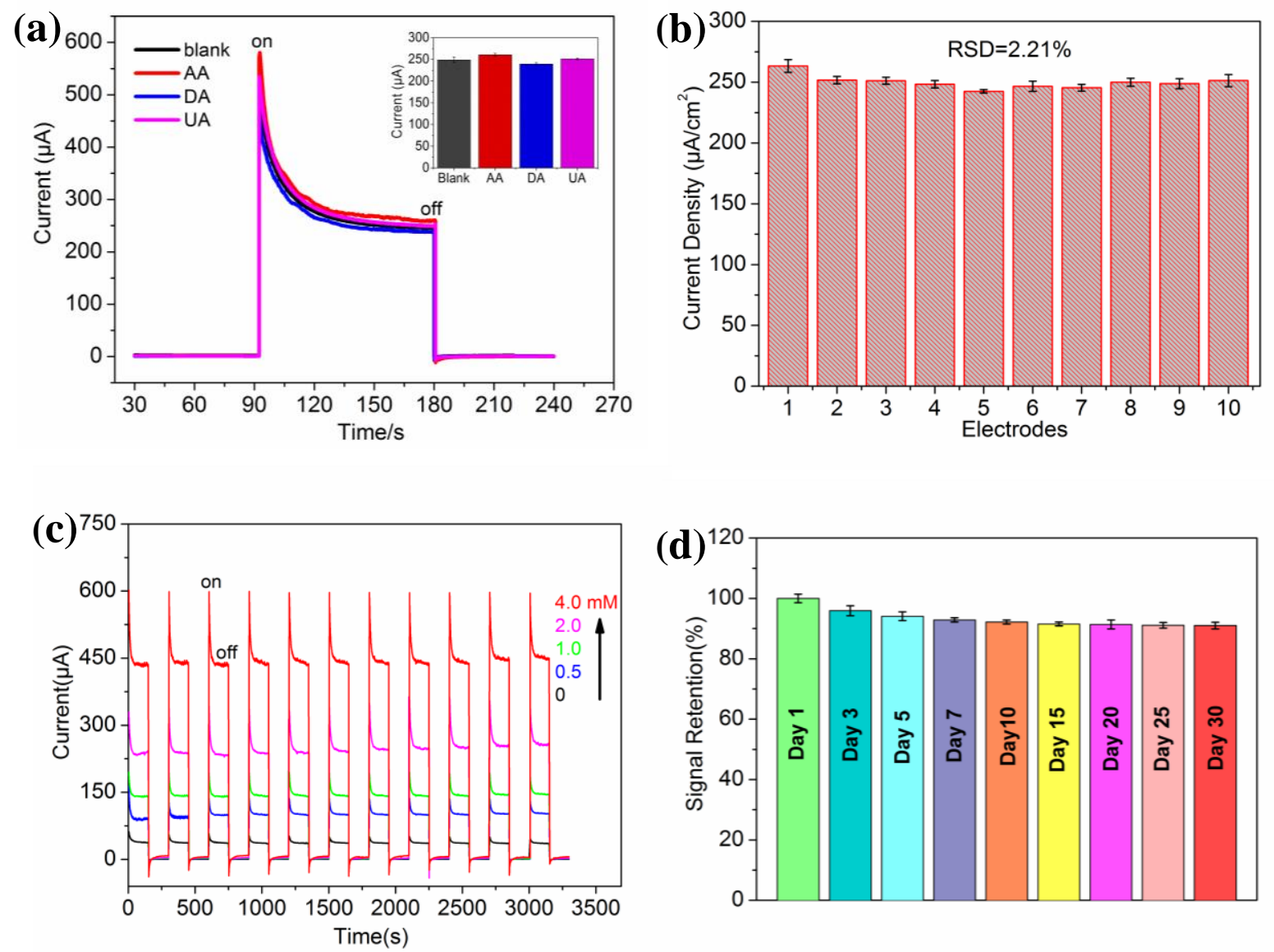
Table 1 Detection of glucose in human serum samples.

\begin{tabular}{ccccc}
\hline Sample & $\begin{array}{l}\text { Concentration } \\
\text { measured by } \\
\text { hospital }(\mathrm{mM})\end{array}$ & $\begin{array}{l}\text { Concentration } \\
\text { measured by the } \\
\text { PEC sensor }(\mathrm{mM})\end{array}$ & $\begin{array}{c}\text { Recovery } \\
(\%)\end{array}$ & $\begin{array}{c}\text { RSD (\%) } \\
(\mathrm{n}=5)\end{array}$ \\
\hline 1 & 4.8 & 4.94 & 102.9 & 5.5 \\
2 & 5.1 & 4.99 & 97.8 & 6.9 \\
3 & 5.6 & 5.46 & 97.5 & 4.1 \\
\hline
\end{tabular}




\section{Biographies}

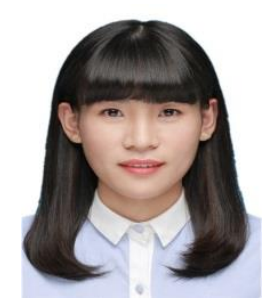

Shan Wang received her MS degree from Beihang University in 2018. Then she joined Prof. Hao's group as a PhD student. Her work focuses on surface chemical analysis and electrochemical sensors.

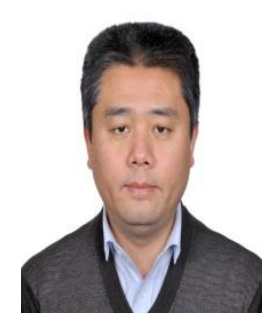

Weichang Hao received his B.S. degree (1997) in Materials Engineering from Northeastern University and Ph.D degree (2003) in Materials Physics from Lanzhou University. Then he worked as postdoctoral fellow in Department of Physics of Beihang Univeristy (2003-2005). From 2005 and then, he was a faculty member in Department of Physics, Beihang University. He has been a full Professor of Condensed Matter Physics since 2013. He also conducted research as a Visiting Scholar inTokyo Institute of Technology (Tokyo Tech) $(2008,2014)$ and University of Wollongong (UOW) (2011-2012). His scientific interest is focused on the electronic structure of oxide materials, oxide materials for environmental purification and energy conversation and 2D nanostructured materials and related devices. He has published 100 peer reviewed journal articles, and the work was cited more than 1500 times. 